\title{
Docentes médicos e internos do curso de medicina estão preparados para uma boa prática médica no atendimento aos portadores de doença falciforme?
}

\author{
Medical doctors and internal medicine students: are they prepared to \\ care of sickle cell disease patients?
}

Marjorie Orquisa Carlos $^{1}$, Patrícia Brigatte ${ }^{2}$, Helio Alvimar Loterio ${ }^{3}$

Carlos MO, Brigatte P, Loterio HA. Docentes médicos e internos do curso de medicina estão preparados para uma boa prática médica no atendimento aos portadores de doença falciforme? / Medical doctors and internal medicine students: are they prepared to care of sickle cell disease patients? Rev Med (São Paulo). 2018 mar.-abr.;97(2):128-34.

RESUMO: Doença falciforme é uma denominação dada ao conjunto de hemoglobinopatias. Estima-se que existam no Brasil de 25 mil a 30 mil portadores de doença falciforme e que surjam, anualmente, 3.500 novos casos. No estado de São Paulo, temos uma incidência de 1:4000 nascidos vivos. Ainda não há dados consistentes sobre a mortalidade e a letalidade da doença falciforme no Brasil. É importante ressaltar que os profissionais de saúde sejam devidamente treinados para que as taxas de mortalidade continuem a decrescer. Para tanto, este trabalho tem como objetivo analisar a capacitação de estudantes internos de medicina, bem como seus docentes em relação a doença falciforme. Materiais e métodos: Foi realizado um estudo transversal quantitativo, com alunos do $5^{\circ}$ e $6^{\circ}$ ano e docentes médicos da Universidade Cidade de São Paulo. Foi aplicado um questionário com 5 perguntas. Resultados e discussão: Os resultados mostraram que os alunos e os docentes sabiam o que era doença falciforme; com relação ao diagnóstico a maioria dos estudantes tinha este conhecimento e todos os docentes saberiam diagnosticá-la; com relação as manifestações clínicas, a maioria dos alunos souberam responder à pergunta e 100\% dos docentes responderam que sim; com relação a quarta pergunta tanto os alunos quanto os docentes conheciam com maior frequência as manifestações gerais observadas. E com relação ao tratamento, foi observado que os alunos das etapas $9^{\mathrm{a}}$ e $12^{\mathrm{a}}$, bem como os docentes médicos tinham o devido conhecimento do tratamento das manifestações agudas da doença falciforme, ao contrário dos alunos da $10^{\mathrm{a}}$ e $11^{\mathrm{a}}$ etapas, que relataram desconhecer o tratamento destas manifestações. Nossos estudos apontam para a importância do adequado conhecimento da doença, seu diagnóstico, suas manifestações clínicas e tratamento no meio acadêmico para melhorar a qualidade de vida dos pacientes com esta doença, bem como diminuir significativamente a taxa de mortalidade de pacientes portadores de doença falciforme.

Descritores: Anemia falciforme; Anemia falciforme/ epidemiologia; Pessoal de saúde; Conhecimentos, atitudes e prática em saúde; Educação médica/recursos humanos.

ABSTRACT: Sickle cell disease is a denomination given to hemoglobinopathies's group. It is estimated that there are 25,000 to 30,000 patients with sickle cell disease in Brazil and 3,500 new cases occur each year. In the state of São Paulo, we have an incidence of 1: 4000 live births. Doesn't have data on mortality and lethality sickle cell disease in Brazil. It is important to emphasize

1. Estudante de Medicina da Universidade Cidade de São Paulo. ORCID: https://orcid.org/0000-0001-8487-5629. E-mail: mama. orquisa@hotmail.com.

2. Graduada em Ciências Biológicas pela Universidade Federal de Juiz de Fora, Mestrado e Doutorado em Patologia Experimental Comparada pela Faculdade de Medicina Veterinária e Zootecnia da Universidade de São Paulo - USP; Tutora e Pesquisadora Científica da Universidade de Medicina da Universidade Cidade de São Paulo. ORCID: https://orcid.org/0000-0003-2796-4187. E-mail: pattbtte@gmail.com.

3. Doutorado em Medicina (Hematologista) pela Universidade de São Paulo; Membro do NAE (Núcleo de Apoio ao Estudante, da Faculdade de Medicina de Jundiaí), Tutor da Universidade Cidade de São Paulo. ORCID: https://orcid.org/0000-0002-7177-3540. E-mail: hal.jsp@gmail.com.

Endereço para correspondência: Marjorie O. Carlos. Avenida Cassandoca, 1327, ap 21. São Paulo, SP, Brasil. 
that health professionals be trained so that mortality rates continue to decrease. Therefore, this work aims to analyze the training of internal medicine students, as well as their teachers in relation to sickle cell disease. Materials and methods: A quantitative crosssectional study was carried out with 5th and 6th grade students and medical professors from Universidade Cidade de São Paulo. A questionnaire with 5 questions was applied. Results and discussion: The results showed that students and teachers knew what is sickle cell disease; with respect to the diagnosis most of the students had this knowledge and all the teachers would know to diagnose it; with respect to the clinical manifestations, most of the students knew how to answer the question and $100 \%$ of the teachers answered yes; with respect to the fourth question both students and teachers were more often aware of the general

\section{INTRODUÇÃO}

A anemia falciforme é uma doença genética, Beta da globina, conduzindo a uma alteração na molécula de hemoglobina e na forma das hemácias para uma forma de foice, na ausência de oxigênio. Representada pelo estado homozigoto para a hemoglobina S (SS), corresponde à forma mais grave das Síndromes Falciformes. A denominação "anemia falciforme" é reservada para a forma da doença que ocorre nesses homozigotos SS. Além disso, o gene da $\mathrm{HbS}$ pode combinar-se com outras anormalidades hereditárias das hemoglobinas, como hemoglobina $\mathrm{C}$ $(\mathrm{HbC})$, hemoglobina $\mathrm{D}(\mathrm{HbD})$, beta-talassemia, gerando combinações que também são sintomáticas, constituindo o grupo denominado doença falciforme $e^{1,2,3,4}$.

A doença falciforme é uma das enfermidades genéticas e hereditárias mais comuns no Brasil ${ }^{1}$. Dados oferecidos pelo Ministério da Saúde, referidos por Cançado e Jesus $^{5}$, estimam que existam no Brasil de 25 mil a 30 mil portadores de doença falciforme e que surjam, anualmente, 3.500 novos casos. No estado de São Paulo, temos uma incidência de 1:4000 nascidos vivos ${ }^{6}$.

Estima-se a existência de pelo menos dois milhões de portadores da $\mathrm{HbS}$ (heterozigotos) no mundo ${ }^{7}$. No Brasil, a doença é predominante entre indivíduos negros e pardos, também ocorrendo nos brancos. No sudeste do Brasil, a prevalência média de heterozigotos (portadores) é de $2 \%$, valor que sobe a cerca de $6-10 \%$ entre negros. Este percentil sobe cerca de $0,1 \%$ a $0,3 \%$ nesta população ${ }^{5}$. Com relação a taxa de mortalidade no Brasil, ainda não há dados consistentes sobre a mortalidade e a letalidade ${ }^{6}$.

Sabe-se, entretanto, que as taxas de mortalidade de pacientes com anemia falciforme vêm diminuindo significativamente ao longo das últimas décadas. Esse fato deve-se a implantação de programas para o diagnóstico precoce e consequente instituição de medidas profiláticas, já a partir do período neonatal ${ }^{7}$.

Para que níveis de mortalidade continuem reduzindo, os profissionais da saúde precisam de cada vez manifestations observed. Regarding the treatment, it was observed that the students of the 9th and 12th stages, as well as the medical teachers had the proper knowledge of the treatment of the acute manifestations of sickle cell disease, unlike the students of the 10th and 11th stages, who reported unknowing the treatment of these manifestations. Our studies point to the importance of adequate knowledge of the disease, its diagnosis, its clinical manifestations and treatment in the academic environment to improve the quality of life of patients with this disease, as well as significantly reduce the mortality rate of patients with sickle cell disease.

Keywords: Anemia, sickle cell; Anemia, sickle cell/epidemiology; Health personnel; Health knowledge, attitudes, practice; Education, medical/manpower.

mais conhecimento a respeito da doença, para saberem reconhecer um paciente acometido, uma vez que eles podem apresentar diferentes manifestações clínicas em diferentes sistemas. É importante ressaltar que os profissionais de saúde sejam devidamente treinados para que as taxas de mortalidade continuem a decrescer. Para tanto, este trabalho tem como objetivo analisar a capacitação de estudantes internos de medicina, bem como seus docentes em relação a doença falciforme.

\section{MATERIAL E MÉTODOS}

O presente estudo quantitativo de abordagem transversal foi realizado por meio de um questionário aplicado em internos do curso de medicina, nos quais $38,49,47$ e 38 dos alunos eram da $9^{\mathrm{a}}, 10^{\mathrm{a}}, 11^{\mathrm{a}}$ e $12^{\mathrm{a}}$ etapas respectivamente. Cabe ressaltar que a $9^{\mathrm{a}}$ e a $10^{\mathrm{a}}$ etapas correspondem ao $5^{\circ}$ ano do curso tradicional de medicina, sendo a $11^{\mathrm{a}}$ e a $12^{\mathrm{a}}$ etapas correspondentes ao $6^{\circ}$ ano deste curso. Docentes médicos (22 indivíduos), independentemente de suas especialidades, participaram da pesquisa. O questionário foi aplicando dentro da Universidade Cidade de São Paulo (sistema PBL - Practice based learning), apenas para alunos e professores que frequentam esta. O questionário aplicado foi baseado em um já validado (Comitê de Ética em Pesquisa da NOVAFAPI, CAAE n ${ }^{\circ}$ 0379.0.043.000-11) e aplicado por Laise Maria Formiga Moura Barroso ${ }^{10}$, que foi modificado e aprovado.

Os dados foram coletados após consentimento informado e somente após aprovação pelo Comitê de Ética em Pesquisa pelo número CAAE: 56600616.7.0000.0064. A abordagem das participantes partiu de um convite informal dos pesquisadores, foram expostos os objetivos do trabalho e esclarecidas possíveis dúvidas.

Os dados coletados foram separados em gráficos dependendo da etapa que o aluno cursava. Com relação a quarta pergunta "Caso sim, quais são elas? Cite-as", os resultados apresentados foram separados por grandes sistemas, uma vez que as respostas dadas pelos alunos podiam 
estar relacionadas a sistemas diversos. Portanto, respostas como anemia e hepatoesplenomegalia foram direcionadas para o sistema linfo-hematopoético. Respostas como dor óssea, artrite, mialgia, dor em membros, miastenia e síndrome mão e pé englobados no sistema osteoarticularmuscular. O sistema cardiopulmonar, englobou respostas como trombose, crises vasooclusivas, dispneia, síndrome torácica aguda, dor torácica, insuficiência respiratória, tromboembolismo pulmonar. O sistema urogenital, englobou respostas como priaprismo, insuficiência renal e retardo no crescimento (devido a alterações hormonais que ocorrem no sistema reprodutor). Respostas como palidez, cianose, úlceras de perna e icterícia englobaram "cutâneo-mucosa". O sistema gastrointestinal englobou somente dores abdominais. O sistema nervoso central, englobou acidente vascular encefálico isquêmico, acidente vascular encefálico hemorrágico e cefaleia. Finalmente as manifestações gerais, englobou astenia, crises álgicas, infecções recorrentes, fadiga, mal-estar, tontura e febre.

É importante ressaltar, portanto, que as respostas dos alunos relacionadas a exatamente quais manifestações clínicas observadas nos pacientes com doença falciforme (pergunta 4), foram agrupadas nos sistemas descritos acima. Desta forma, o número de alunos partícipes do presente estudo não corresponde ao total de respostas apresentadas.

As questões que seguem são para avaliar seu conhecimento a respeito da doença falciforme. Responda o que souber.

Pergunta 1. Você sabe o que é doença falciforme? 1.Sim 2.Não

Pergunta 2. Sabe como se faz o diagnóstico da doença falciforme? 1. Sim 2. Não
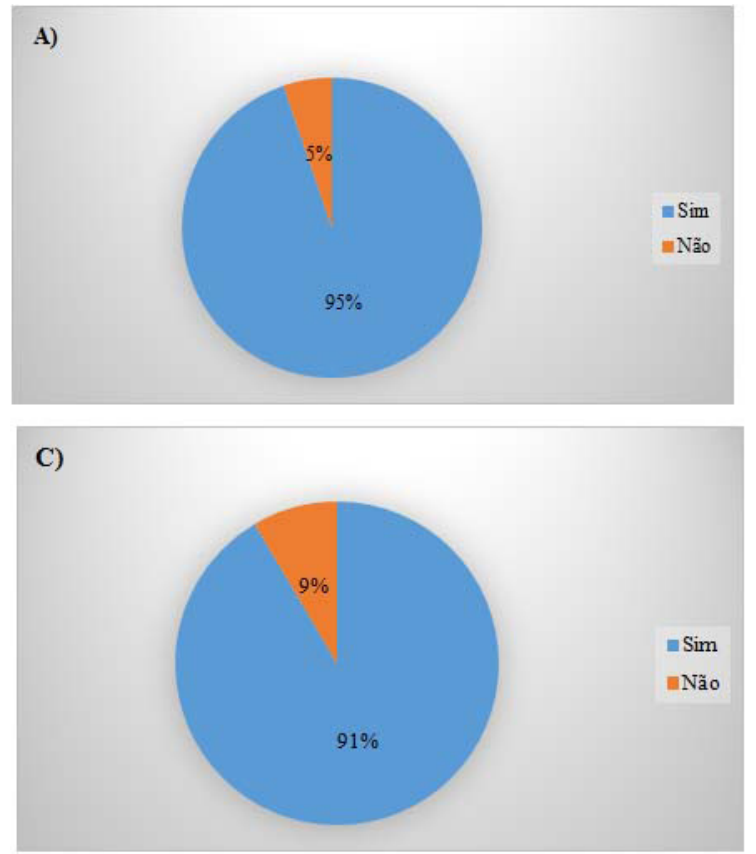

Figura 1. Alunos da $9^{\mathrm{a}}(\mathrm{A}), 10^{\mathrm{a}}(\mathrm{B}), 11^{\mathrm{a}}$ (C) e $12^{\mathrm{a}}$ (D) etapas sabem fazer o diagnóstico da doença falciforme
Pergunta 3. Conhece quais são as principais manifestações clínicas do paciente com doença falciforme? 1 . Sim 2. Não

Pergunta 4. Caso sim, quais são elas? Cite-as.

Pergunta 5. Sabe como tratar as manifestações agudas da doença? 1. Sim 2. Não

\section{RESULTADOS}

A primeira pergunta "Você sabe o que é doença falciforme?", de todas as turmas do internato, $9^{\mathrm{a}}, 10^{\mathrm{a}}, 11^{\mathrm{a}}$ e $12^{\mathrm{a}}$ etapa, obtiveram "sim" como resposta (dados não mostrados). Com relação aos docentes médicos, também houve $100 \%$ nas respostas "sim" quanto a essa pergunta (dados não mostrados).

Com relação a segunda pergunta "Sabe como se faz o diagnóstico da doença falciforme? ", foi observado que a grande maioria dos alunos souberem responder à pergunta, independentemente da etapa cursada.

É interessante notar que os alunos da $10^{\mathrm{a}}$ etapa (Figura 1B) foram os que mais relataram ter conhecimento sobre o diagnóstico de doença falciforme (14\%).

Ainda em relação a doença falciforme, os docentes médicos $(100 \%)$ relataram terem conhecimento do diagnóstico da doença (dados não mostrados).

Foi observado no seguinte questionário que a maioria dos alunos souberam responder à pergunta relacionada ao conhecimento das manifestações clínicas do paciente com doença falciforme.

Os alunos da $11^{\mathrm{a}}$ etapa (Figura $2 \mathrm{C}$ ) foram os que mais relataram ter conhecimento das manifestações clínicas da doença falciforme (13\%).
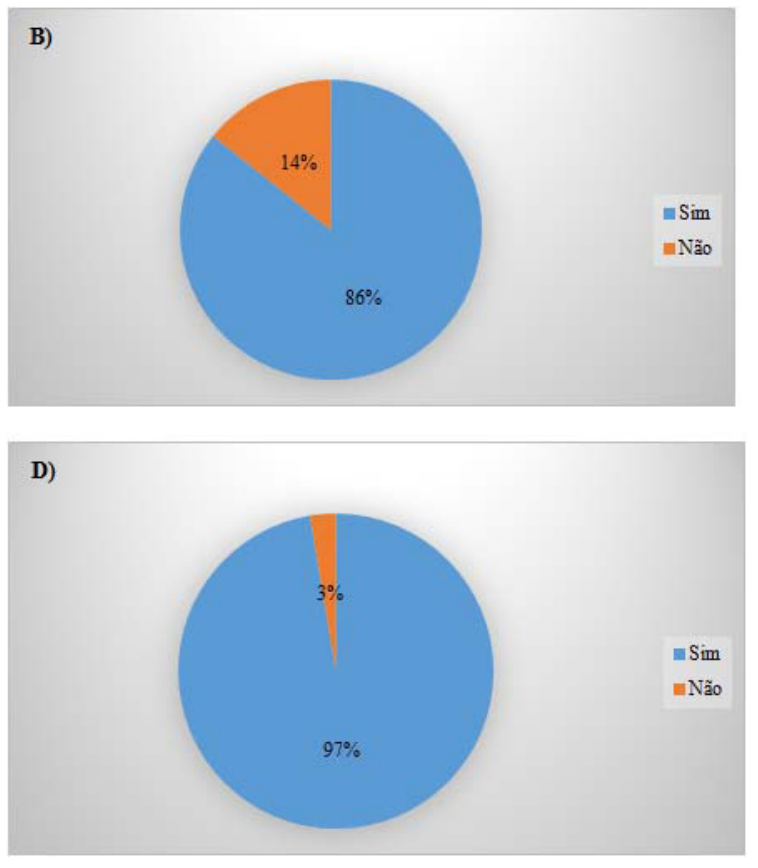

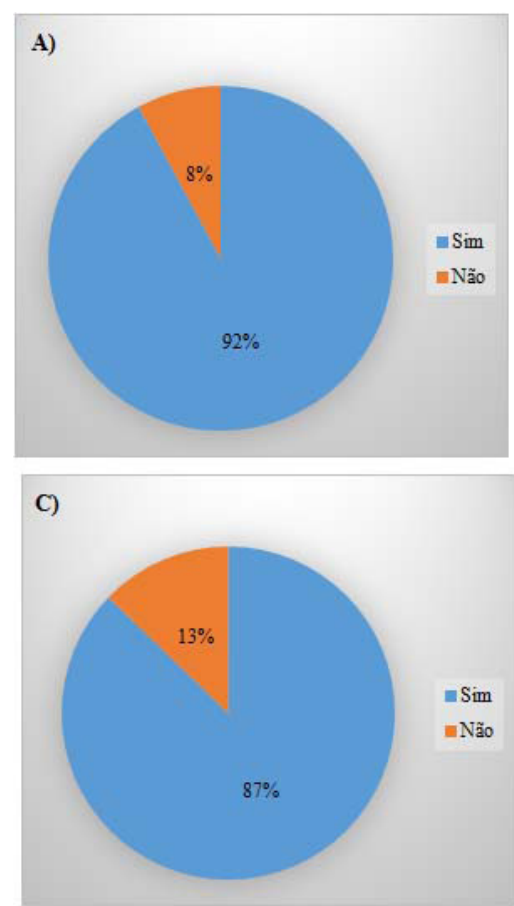
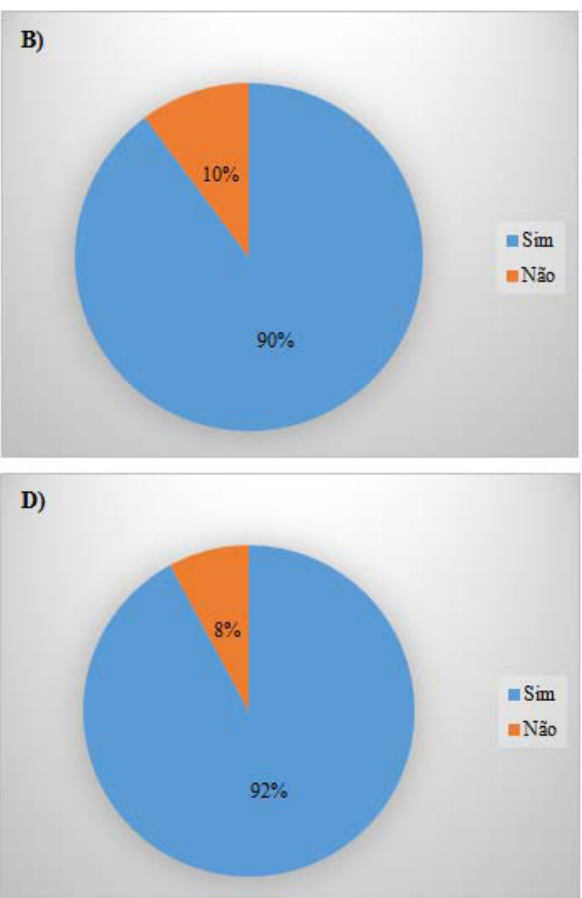

Figura 2. Alunos da $9^{\mathrm{a}}(\mathrm{A}), 10^{\mathrm{a}}(\mathrm{B}), 10^{\mathrm{a}}(\mathrm{B}), 11^{\mathrm{a}}$ (C) e $12^{\mathrm{a}}$ (D) etapas conhecem as manifestações clínicas do paciente com doença falciforme

Assim como na questão anterior, todos os docentes médicos $(100 \%)$ responderam novamente "sim" para essa pergunta (dados não mostrados).

Foi questionado, ainda, se os alunos das $9^{\text {a }}$, $10^{\mathrm{a}}, 11^{\mathrm{a}}$ e $12^{\mathrm{a}}$ etapas sabiam quais eram exatamente as manifestações clínicas na doença. Como já descrito no "Material e Métodos", as respostas dos alunos relacionadas a exatamente quais manifestações clínicas observadas nos pacientes com doença falciforme (pergunta 4) foram agrupadas em sistemas. Desta forma, o número de alunos partícipes do presente estudo não corresponde ao total de respostas apresentadas.

Os resultados mostram que tanto alunos quanto docentes conheciam com maior frequência as manifestações gerais observadas (astenia, crises álgicas, infecções recorrentes, fadiga, mal-estar, tontura e febre - Figuras 3A, B, C, D e Figura 4).

Cabe ressaltar que a manifestação do sistema gastrointestinal (dores abdominais) foi a menos citada (Figuras 3A, B, C, D e Figura 4).

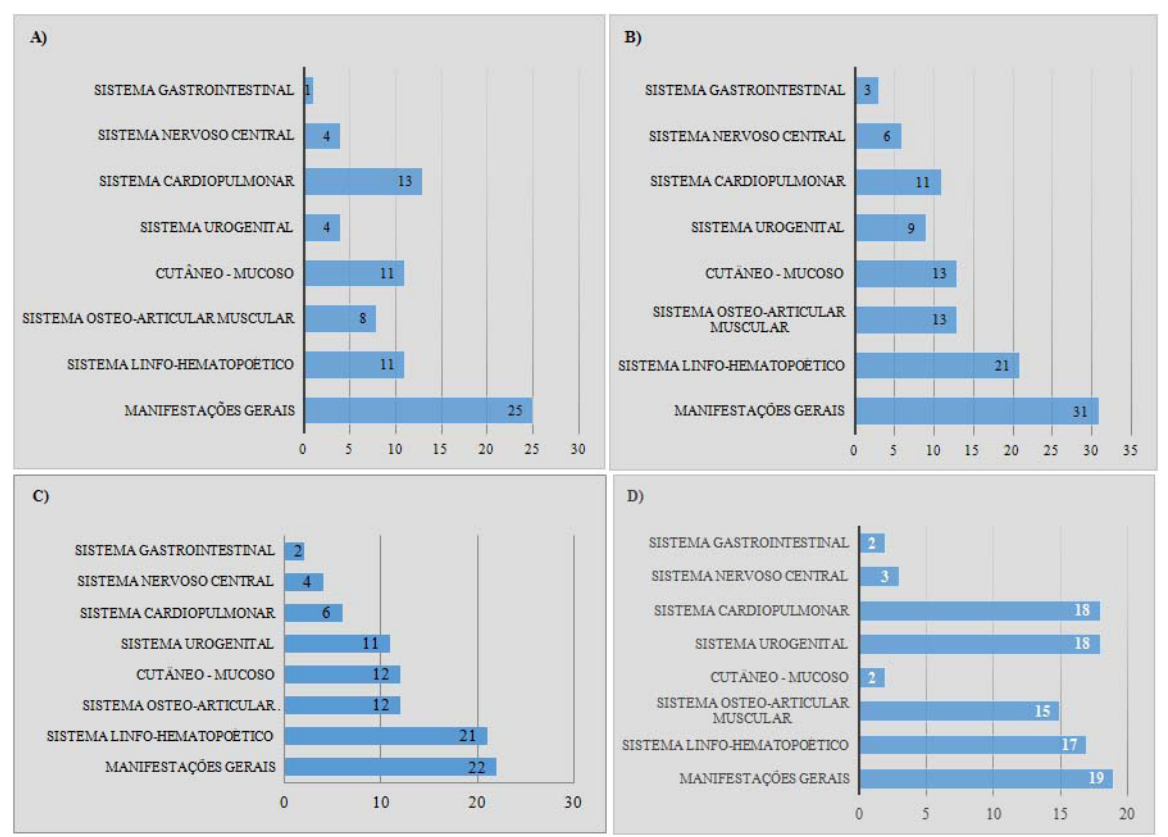

Figura 3. Alunos da $9^{\mathrm{a}}(\mathrm{A}), 10^{\mathrm{a}}(\mathrm{B}), 10^{\mathrm{a}}(\mathrm{B}), 11^{\mathrm{a}}$ (C) e $12^{\mathrm{a}}$ (D) etapas conhecem quais são as manifestações clínicas relacionadas a doença falciforme 


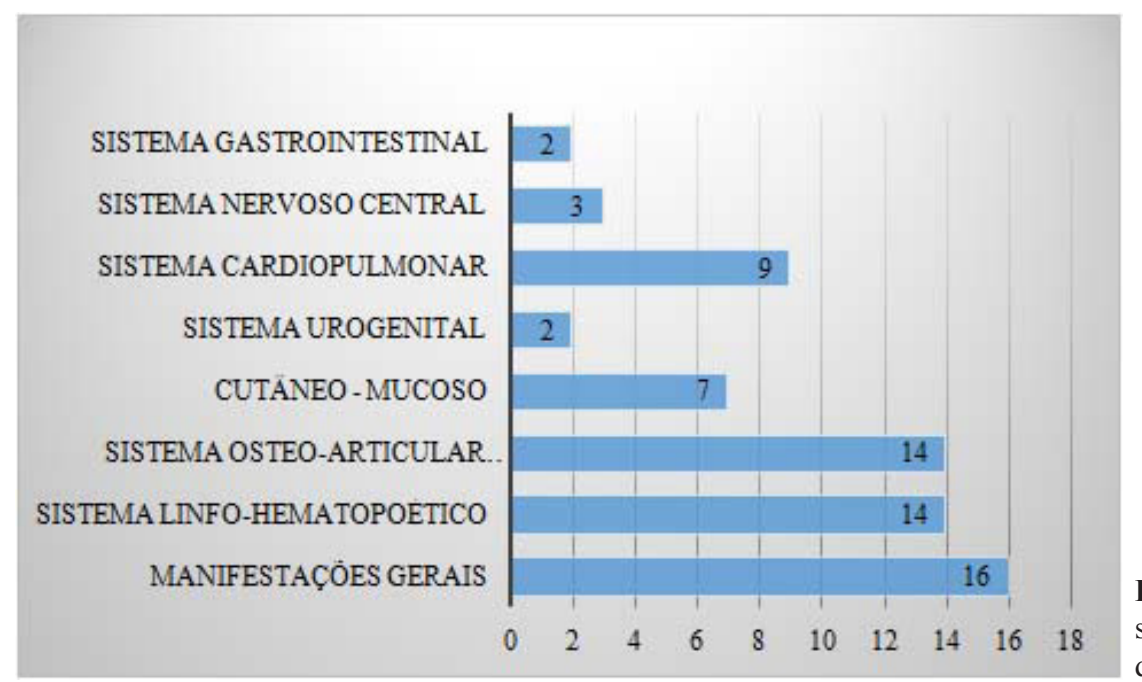

Figura 4. Docentes médicos conhecem quais são as manifestações clínicas relacionadas à doença falciforme

Finalmente, com relação a quinta pergunta "Sabe como tratar as manifestações agudas da doença?", foi observado que os alunos das etapas $9^{\mathrm{a}}$ e $12^{\mathrm{a}}$ (Figuras $5 \mathrm{~A}$ e D), bem como os docentes médicos (Figura 6) tinham
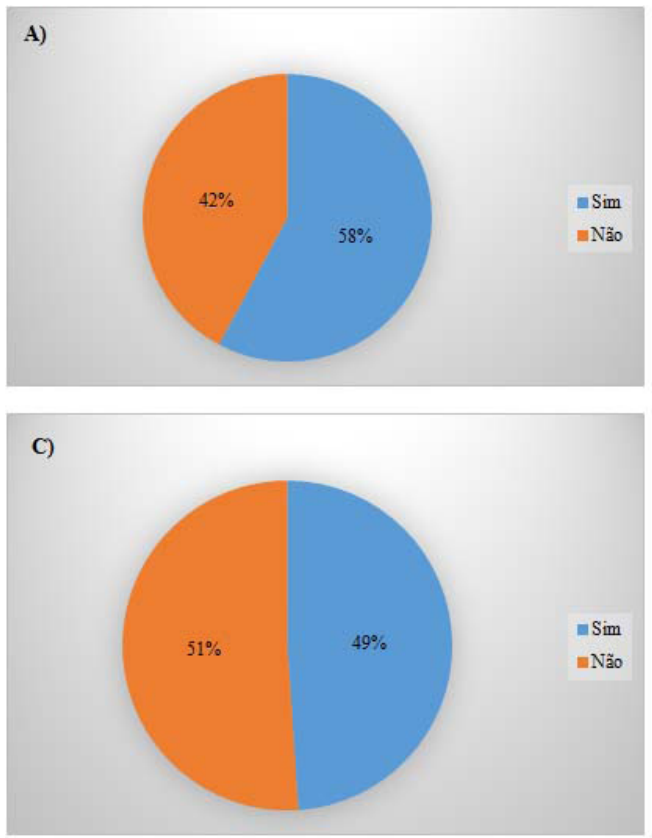

Figura 5. Alunos da $9^{\mathrm{a}}(\mathrm{A}), 10^{\mathrm{a}}(\mathrm{B}), 10^{\mathrm{a}}(\mathrm{B}), 11^{\mathrm{a}}(\mathrm{C})$ e $12^{\mathrm{a}}(\mathrm{D})$ : tratamento das manifestações agudas da doença falciforme

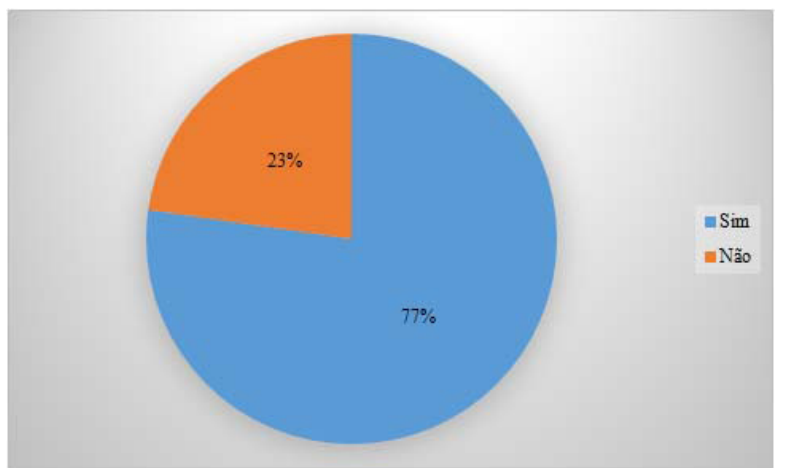

Figura 6. Docentes médicos conhecem o tratamento das manifestações agudas da doença falciforme o devido conhecimento do tratamento das manifestações agudas da doença falciforme. Ao contrário, os alunos da $10^{\mathrm{a}}$ e $11^{\mathrm{a}}$ etapas (Figuras $5 \mathrm{~B}$ e C) relataram desconhecer o tratamento destas manifestações.

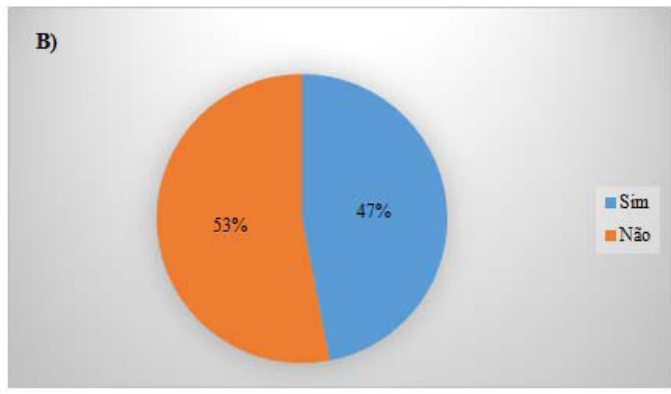

D)

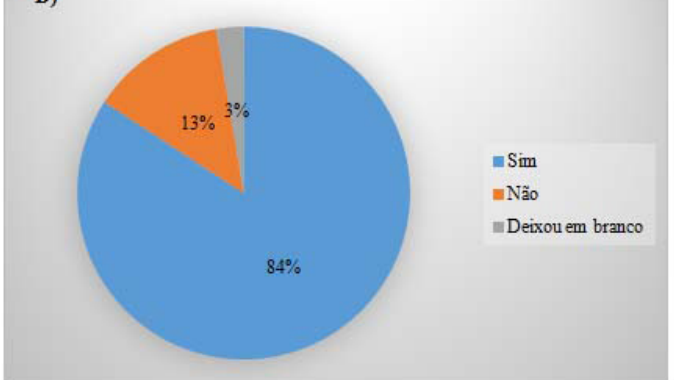

\section{DISCUSSÃO}

A anemia falciforme é uma doença genética, hereditária e multissistêmica, caracterizada pela presença de eritrócitos anormais, devido a presença da HbS. Quando desoxigenada, a $\mathrm{HbS}$ se polimeriza, gerando perda de cátions e água, danificando assim os eritrócitos. Essas células danificadas apresentam anormalidades fisicoquímicas, resultando em anemia hemolítica e vaso-oclusão. Sabendose disso, uma série de complicações podem ser causadas: disfunção vascular-endotelial, deficiência funcional de óxido nítrico, inflamação, estresse oxidativo e lesão de reperfusão, hipercoagulabilidade, aumento da adesividade de neutrófilos e ativação de plaquetas ${ }^{3,4,8}$. 
Embora a caracterização da doença falciforme seja complexa, o presente trabalho mostrou que a grande maioria dos estudantes e docentes sabem o que é a doença falciforme e sabem diagnosticá-la.

$\mathrm{O}$ exame de triagem neonatal consiste na coleta de gotas de sangue do calcanhar da criança (teste do pezinho). Exige-se que essa coleta aconteça após 48 horas da primeira alimentação do recém-nascido, e até o quinto dia útil de vida da criança, na unidade de saúde mais próxima da residência dos responsáveis. Na Atenção Básica, a criança também deverá receber as primeiras vacinas e os cuidados iniciais necessários. A partir dos 4 meses de idade, o diagnóstico pode ser feito por quaisquer das metodologias existentes para eletroforese de hemoglobina ${ }^{6}$.

Quando a detecção da doença falciforme se faz nos testes de triagem neonatal, o diagnóstico possibilita o início de cuidados específicos exigidos, considerando-se que a precocidade e a integralidade da atenção podem ser determinantes na limitação dos agravos. Nos cuidados iniciais, a atenção primária a saúde tem o dever de acompanhar a criança em seu desenvolvimento e a família: aleitamento materno, introdução de alimentos, higiene, vacinas, saúde oral, além de outras indicações específicas para a doença. Esta família deve ser devidamente preparada para o autocuidado - e a assistência nesse sentido precisa ser multiprofissional e humanizada. Entende-se por humanização, além de se dispor de um ambiente confortável para o atendimento das pessoas, levar em consideração que seu acolhimento pelos trabalhadores de saúde precisa ocorrer num plano efetivo de atenção, solidariedade e sem qualquer preconceito ou estigma ${ }^{6,9}$.

O reconhecimento e o diagnóstico são fundamentais para a eliminação da taxa de mortalidade dos indivíduos com doença falciforme, uma vez que estes pacientes estão suscetíveis a inúmeras doenças graves. Conforme exposto no Caderno "Doença Falciforme Diretrizes Básicas da Linha De Cuidado", crianças com doença falciforme até 5 anos de idade, sem cuidados de saúde, têm mortalidade de $80 \%$ (vida média de 8 anos), comparativamente aquelas que possuem cuidados de saúde, com 1,8\% de mortalidade (vida média de 45 anos).

Quando este reconhecimento e diagnóstico pelo profissional de saúde não são adequados, as manifestações clínicas aparecem no paciente com doença falciforme.

As manifestações são diversas e podem acometer diferentes sistemas. No gastrointestinal e abdominal pode haver crises de dor, cálculos biliares, icterícia obstrutiva, hepatopatia; no sistema nervoso central, acidente isquêmico transitório, infarto, hemorragia cerebral; no cardiopulmonar, cardiomegalia, insuficiência cardíaca, infarto pulmonar, pneumonia; no urogenital, priapismo, hipostenúria, insuficiência renal crônica; na superfície cutânea-mucosa, pode apresentar palidez, icterícia e úlceras; no osteoarticular, dores, necrose asséptica da cabeça do fêmur, gnatopatia; nos olhos, retinopatia proliferativa, glaucoma; sistema hematopoiético, temos anemia, asplenia, esplenomegalia crônica e nas manifestações gerais, retardo da maturação sexual e maior suscetibilidade a infecções ${ }^{2,3,4,10}$. A síndrome torácica aguda é um tipo particularmente perigoso de crise vaso-oclusiva envolvendo os pulmões, que tipicamente se apresenta com febre, tosse, dor torácica e infiltrados pulmonares. A inflamação pulmonar (como a que pode ser induzida por infecção simples) faz com que o fluxo sanguíneo se torne mais lento e "semelhante ao baço", promovendo falcização e vaso-oclusão. Isso compromete a função pulmonar, criando um círculo potencialmente fatal de agravamento da hipoxemia pulmonar e sistêmica, falcização e vaso-oclusão ${ }^{8}$.

No presente trabalho de pesquisa, foi observado que os alunos do internato, bem como os docentes sabem reconhecer as manifestações clínicas que ocorrem quando a doença falciforme não é bem diagnosticada. Porém, apenas os estudantes da $9^{\mathrm{a}}, 12^{\mathrm{a}}$ etapas e docentes sabem tratar estas manifestações.

Ao contrário do mostrado em nosso estudo, dados na literatura mostram o desconhecimento de profissionais de saúde em reconhecer manifestações clínicas de pacientes com doença falciforme. Em Minas Gerais ${ }^{11}$, em um estudo localizado em hemocentros da Fundação Hemominas, mesmo existindo um programa de triagem neonatal com rigoroso controle do tratamento, a probabilidade de óbito aos 5 anos (10,6\%) em crianças com doença falciforme foi bem maior que a mortalidade geral. Muitos óbitos foram justificados pelo fato de profissionais da saúde terem dificuldades em reconhecer alguns agravos graves destas crianças acometidas pela doença. No Nordeste ${ }^{12}$, em um estudo aplicado na Atenção Básica, com o objetivo de avaliar os profissionais de saúde, mostrou-se que eles precisam de um melhor preparo técnico para lidar com pacientes com doença falciforme. Foi visto que mais da metade dos profissionais tiveram um conhecimento classificado inadequado ou irregular da doença falciforme. Além disso, Gomes et al (2013), mostraram que 50\% dos profissionais da área da saúde reconhecem as manifestações clínicas e o manejo com a doença falciforme ${ }^{13}$.

Diante de tudo isso, o profissional de saúde que estiver de plantão no dia de uma crise de dor de um paciente com doença falciforme deve saber como se portar e ajudar o paciente ${ }^{14}$.

Em conclusão, estes dados reforçam a importância do adequado conhecimento da doença, seu diagnóstico, suas manifestações clínicas e tratamento no meio acadêmico para melhorar a qualidade de vida dos pacientes com esta doença, bem como diminuir significativamente a taxa de mortalidade de pacientes portadores de doença falciforme. 


\section{REFERÊNCIAS}

1. Brasil. Agência Nacional de Vigilância Sanitária. Manual de diagnóstico e tratamento de doenças falciformes. Brasília: Anvisa; 2002. Disponível em: http://bvsms.saude.gov.br/ bvs/publicacoes/anvisa/diagnostico.pdf.

2. Zago MA, Falcão RP, Pasquini R. Hematologia: fundamentos e prática. São Paulo: Atheneu; 2004.

3. Piel FB, Steinberg MD, Rees DC. Sickle cell disease. Review article. N Engl J Med. 2017;376:1561-73. doi: 10.1056/ NEJMra1510865.

4. Naik RP, Haywood Jr C. Sickle cell trait diagnosis: clinical and social implications. Hematology Am Soc Hematol Educ Program. 2015;2015:160-7. doi: 10.1182/ asheducation-2015.1.160.

5. Cançado RD, Jesus, JA. A doença falciforme no Brasil. Rev Bras Hematol Hemoter. 2007;29(3):204-6. http://dx.doi. org/10.1590/S1516-84842007000300002.

6. Brasil. Ministério da Saúde. Secretaria de Atenção à Saúde, Departamento de Atenção Especializada e Temática. Doença falciforme diretrizes básicas da linha de cuidado. Brasília (DF); 2015. Disponível em: http://bvsms.saude.gov.br/bvs/ publicacoes/doenca_falciforme_diretrizes_basicas_linha_ cuidado.pdf.

7. Padua AI, Martinez JAB. Anemia falciforme: uma importante causa potencial de hipertensão pulmonar no Brasil. J Bras Pneumol (São Paulo). 2012;38(1):143-4. http://dx.doi. org/10.1590/S1806-37132012000100021.

8. Kumar V, Abbas AK, Fausto N, Mitchell RN. Robbins - bases patológicas das doenças. 8a ed. Rio de Janeiro: Elsevier; 2010.

9. Brasil. Ministério da Saúde. Doença falciforme - o que se deve saber sobre herança genética. Brasília: Secretaria de Atenção à Saúde Departamento de Atenção Hospitalar e de Urgência; 2014. Disponível em: http://www.nupad.medicina.ufmg.br/ wp-content/uploads/2016/12/O-que-se-deve-saber-sobreHeranca-Genetica.pdf.
10.Lanzkron S, Haywood Jr C. The five key things you need to know to manage adult patients with sickle cell disease. Hematology Am Soc Hematol Educ Program. 2015;2015:420-5. doi: 10.1182/asheducation-2015.1.420.

11. Fernandes APPC, et al. Mortalidade de crianças com doença falciforme: um estudo de base populacional. J. Pediatr. (Rio J.). 2010;86(4):279-84. http://dx.doi.org/10.1590/S002175572010000400006 .

12. Barroso LMFM. Conhecimento de profissionais da estratégia saúde da família sobre a anemia falciforme [Dissertação]. Teresina: Programa de Mestrado Saúde da Família, Centro Universitário UNINOVAFAPI; 2013 [citado 28 jan. 2016]. Disponível em: http://mestrado. uninovafapi.edu.br/wp-content/uploads/2013/08/LAISEMARIA-FORMIGA-MOURA-BARROSO-email.pdf.

13. Gomes LMX, Vieira MM, Reis TC, Barbosa TLA, Caldeira AP. Understanding of technical education level professionals regarding sickle cell disease: a descriptive study. Online Braz J Nurs. 2013;12(2):482-90. Available from:http://www.objnursing.uff.br/index.php/nursing/ article/view/4034.

14. Brasil. Ministério da Saúde. Secretaria de Atenção à Saúde. Departamento de Atenção Especializada. Manual de condutas básicas na doença falciforme. Brasília: Secretaria de Atenção à Saúde Departamento de Atenção Especializada; 2006. (Série A. Normas e manuais técnicos). Disponível em: http:// bvsms.saude.gov.br/bvs/publicacoes/manual_condutas_ doenca_falciforme.pdf.

15. Bergel SD. Ten years of the Universal Declaration on Bioethics and Human Rights. Rev Bioet. 2015;23(3):44655. http://dx.doi.org/10.1590/1983-80422015233081.

16. Conselho Regional de Medicina do Estado de São Paulo CREMESP. Código de Ética Médica: Código de Processo Ético Profissional, Conselhos de Medicina, Direitos dos Pacientes. São Paulo; 2013. 